\title{
CARLOS GARCÍA GUAL, JAVIER GOMÁ LANZÓN, FERNANDO SAVATER. MUCHAS FELICIDADES. TRES VISIONES Y MÁS DE LA IDEA DE FELICIDAD \\ Gabriel Laguna Mariscal \\ Universidad de Córdoba glaguna@uco.es
}

Received: 1 April 2015 Accepted: 15 April 2015

Carlos García Gual, Javier Gomá Lanzón, Fernando Savater. Muchas felicidades. Tres visiones y más de la idea de felicidad. Madrid: Ariel, 2015, 207 pp. ISBN: 978-84-344-1892-9.

Nos encontramos ante un libro híbrido, facticio y sobrevenido (tres cualidades que, en cierta medida, se implican). Híbrido, porque es una mezcla de libro de auto-ayuda, divulgación filosófica y entrevistas. Facticio, porque consta por aluvión de tres partes muy heterogéneas. Y sobrevenido, porque todo apunta a que la idea de publicar este libro surgió secundariamente para aprovechar los materiales disponibles y como respuesta comercial, algo oportunista, a la demanda de libros de auto-ayuda sobre la felicidad. Todas estas cualidades (o defectos), sin embargo, no restan completamente valor al libro.

La obra consta de tres partes, como se intenta justificar en el prólogo (pp. 7-8), redactado por el editor literario Gonzalo Torné. La primera sección (9-53), titulada "Epicuro y tres más", consiste en la transcripción revisada de las intervenciones en la conferencia colectiva "Filosofía de la felicidad" de Carlos García Gual, Javier Gomá Lanzón y Fernando Savater, en el marco del programa La noche de los libros, organizado por la Comunidad de Madrid. El editor no especifica la fecha de esta conferencia, aunque he podido rastrear por la web que fue el 23 de abril de 2014. Esta primera parte del libro estaría más cercana al concepto de divulgación filosófica o alta síntesis. Las tres intervenciones versan sobre el concepto de felicidad según el filósofo helenístico Epicuro. Tanto Fernando Savater como Carlos García Gual adoptan una posición simpatética y encomiástica 
con la figura de Epicuro y especialmente con su ética de la felicidad. Los dos refutan el tópico de que Epicuro aspirara al hedonismo a ultranza como meta de la vida. Y ambos reivindican la vigencia y aplicabilidad de la escuela epicúrea en el mundo moderno. En contraste, Javier Gomá plantea una crítica a la posición de Epicuro, al que no considera un filósofo, sino un terapeuta $(42,45)$. Acepta de Epicuro su aprecio de la amistad: "Me resulta particularmente simpática su ética de la amistad" (51); en cambio, no sintoniza con su ética individualista (45), su desprecio de la fortuna (44-45) y su despreocupación por la muerte (43-44). Para Gomá, la meta de la vida humana no debe ser la felicidad, sino la dignidad (un concepto afín al término latino de decorum, con el que comparte etimología: esto es nota del reseñista, no de Gomá), que consiste básicamente en cumplir con los requisitos de cada etapa vital, sin tener deudas con la vida. La dignidad se alcanzaría estando a la altura de las circunstancias y de los tiempos, con el objetivo de convertir en ejercicio la potencialidad humana (49).

La segunda parte (55-161), más extensa y titulada "Tres visiones de la felicidad", constituye una especie de "second round" sobre la cuestión de la felicidad, ya sin que Epicuro domine el panorama (aunque no desaparezca del todo). Esta parte es el resultado de charlas mantenidas con los tres autores (supuestamente por el editor Gonzalo Torné, aunque no se aclara), charlas que han sido editadas (por Torné) y revisadas (por los entrevistados) hasta adquirir el formato de pequeños ensayos sobre ética vital. Los tres autores presentan su ideal de felicidad según los hitos principales de la historia de la filosofía y según también el propio ideario filosófico. García Gual se centra en la filosofía antigua; Savater, en la filosofía moderna; y Gomá, en la filosofía propia.

Carlos García Gual en el apartado "Los antiguos y la busca de la felicidad" (59-85) elabora una historia de la concepción sobre la felicidad en el pensamiento clásico grecolatino, incluyendo la poesía griega arcaica, Sócrates y Platón, Aristóteles, filósofos helenísticos (cínicos, otra vez Epicuro, escépticos y estoicos), y algunos cultos religiosos (dionisismo, orfismo y cristianismo). García Gual muestra de nuevo su capacidad de amenidad y síntesis. Además, trata sobre una materia que tiene muy estudiada, como se manifiesta conspicuamente en su clásico libro Epicuro, que tras muchas ediciones y reimpresiones se ha convertido merecidamente en un estudio clásico sobre la cuestión. Me gusta especialmente su tratamiento de la influencia de Sócrates en algunos postulados de filósofos helenísticos (65-66): "El precursor de este regreso a la individualidad es, de alguna manera, Sócrates, que fue el ejemplo de sabio (no sólo un teórico, 
sino un modelo de comportamiento ... ) al que aspiraron todas las filosofías helenísticas" (65).

Fernando Savater en su capítulo "Jardines Interiores" (91-140) pasa revista a algunas propuestas sobre la felicidad en la filosofía occidental, incluyendo el pensamiento arcaico griego, Aristóteles, el estoicismo, Epicuro (otra vez) y Spinoza, por el que muestra una curiosa e interesante predilección (107, 137-38). Savater postula la participación ciudadana en política (algo que él mismo ha predicado con el ejemplo), ya que considera que la felicidad individual es dependiente del buen funcionamiento de la colectividad social (113-116). Por otro lado, critica vehementemente la tendencia moderna a cifrar la felicidad en la juventud (98-102), afirmando que también la vejez ofrece buenas cosas (aunque en este punto debería haber citado los argumentos del De senectute de Cicerón). En realidad, Savater renuncia a la consecución de la felicidad, pero sí aspira a una versión modesta de ese estado, a la que denomina simplemente "alegría" (139): esa alegría, en opinión del autor, puede alcanzarse mediante el equilibrio entre la dedicación pública y privada (120-22) y se fomenta con el cultivo de las aficiones personales de cada cual, que en el caso del autor son los estudios humanísticos, especialmente la filosofía y literatura (13340). Me quedo con esto último, que también había sido anticipado en el ciceroniano De senectute.

Finalmente, Javier Gomá en su contribución "El sello" (141-161) deja ya de lado la filosofía anterior (con la excepción de alguna mención a Ortega) y elabora una especie de resumen de su propio sistema ético, que había expuesto en tres libros que constituyen en conjunto la llamada "trilogía de la experiencia de la vida": Imitación y experiencia (2003), Aquiles en el gineceo (2007) y Ejemplaridad pública (2009). Para el autor, todos los seres tienden a su perfección, a su fin: en el caso del hombre, aspira a una perfección que trasciende sus capacidades. El autor llama felicidad a esta perfección. Se trata de una curiosa e interesante definición de la felicidad humana, quizá deudora de Aristóteles y de categorizaciones de la escolástica medieval. Javier Gomá propugna la ejemplaridad ética como meta del ser humano.

La tercera parte del libro es la más mostrenca (por no decir desvergonzada), ya que ha sido diseñada básicamente para llenar páginas, con el efecto colateral de contribuir a la deforestación global: lleva el título de "Felices los felices" (163-207) y consiste en la impresión de frases célebres sobre la felicidad, en número de 41, atribuidas a autores famosos desde Aristóteles a Octavio Paz, pasando por los inevitables Buda, Einstein 
y Gandhi, a razón de una frase por página. La exactitud de las atribuciones no está garantizada, ya que parece que las frases se han obtenido de Internet y de almanaques variados. No se aportan las referencias concretas.

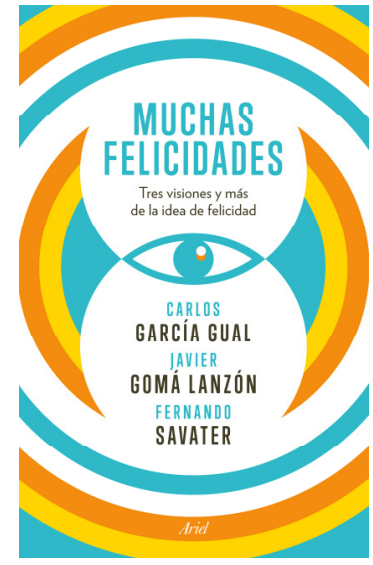

Fig. 1. Cubierta de Muchas felicidades (2015)

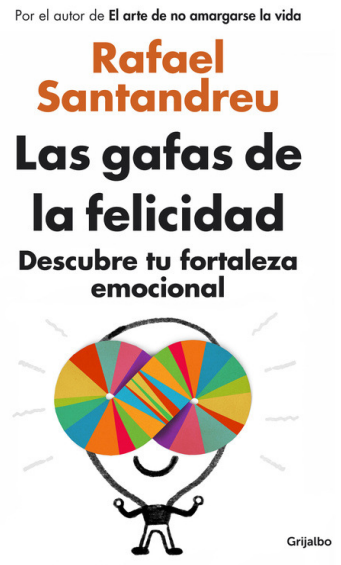

Fig. 2. Cubierta de Las gafas de la felicidad (2014)

En suma, el libro tiene partes interesantes. En general, es agradable de leer. Carece de notas eruditas, de bibliografía y de índice de conceptos o nombres. Pero su principal defecto es que no responde a un "sello" (por usar el concepto de Gomá) editorial, sino que se trata de una publicación oportunista de la editorial para intentar posicionarse en los anaqueles de libros más vendidos en la categoría de No ficción de las grandes superficies, junto a best-sellers recientes del género de auto-ayuda, como los libros de Rafael Santandreu (El arte de no amargarse la vida, Las gafas de la felicidad). La colorida cubierta (Fig. 1) intenta atraer al lector habitual de libros de auto-ayuda (compárese la Fig. 2) y revela la pretensión mercantilista de la editorial, de la que los autores ni posiblemente tampoco el editor literario son responsables (hopefully). Dado el carácter híbrido del libro (auto-ayuda, divulgación filosófica, entrevistas), es de sospechar que no satisfará ni a tirios ni a troyanos y que no alcanzará sus objetivos editoriales en ninguna de las tres facetas. 


\section{Obras citadas}

García Gual, Carlos. Epicuro. Madrid: Alianza Editorial, 2006.

Gomá Lanzón, Javier. Imitación y experiencia. Valencia: Pre-Textos, 2003.

---. Aquiles en el gineceo, o aprender a ser mortal. Valencia: Pre-Textos, 2007.

---. Ejemplaridad pública. Madrid: Taurus, 2009.

Powell, J. G. F. (ed.). M. Tulli Ciceronis De Re Publica, De Legibus, Cato Maior de Senectute, Laelius de Amicitia. Oxford: Clarendon Press, 2006.

Santandreu, Rafael. El arte de no amargarse la vida. Barcelona: Paidós, 2011.

---. Las gafas de la felicidad. Madrid: Grijalbo, 2014. 